\title{
Effects of Maternal Protein-Calorie Malnutrition on the Phospholipid Composition of Surfactant Isolated from Fetal and Neonatal Rat Lungs. Compensation by Inositol and Lipid Supplementation
}

\author{
V. GUARNER, ${ }^{\prime}$ C. TORDET, AND J. R. BOURBON \\ Centre de Biologie Cellulaire, Centre National de la Recherche Scientifique, Ivry-sur-Seine. France.
}

\begin{abstract}
The effects of a maternal protein-calorie malnutrition during gestation and lactation were analyzed on fetal and postnatal lung growth and maturation, including a surfactant fraction isolated from lung tissue. There was a considerable reduction in body weight and in wet and dry lung weights of malnourished pups. Lung protein and DNA concentrations were similar in both groups except in late gestation (lung hyperplasia) and 2 and $15 \mathrm{~d}$ after delivery (hypocellularity). Lung glycogen breakdown was slowed down in malnourished newborns. Surfactant material was decreased the most perinatally and the reduction was more marked than for the nonsurfactant fraction of the lung. Disaturated phosphatidylcholine, the major surface active surfactant component, was decreased the most at birth $(1.70 \pm 0.31 \mathrm{nmol} / \mathrm{mg}$ wet wt versus $3.68 \pm 0.17$ $\mathrm{nmol} / \mathrm{mg}$ in controls, $n=8)$ and on $\mathrm{d} 2(5.04 \pm 0.53 \mathrm{nmol} /$ $\mathrm{mg}$ versus $7.67 \pm 0.44 \mathrm{nmol} / \mathrm{mg}$ in controls, $n=8$ ). There was an apparent recovery in the composition of surfactant in malnourished rats $5 \mathrm{~d}$ after delivery, due in fact to a decrease in controls, and an actual return to normal levels 15 to $20 \mathrm{~d}$ after birth. Postnatal lipid supplementation with Intralipid led to partial recovery on d $\mathbf{1 0}$. Inositol supplementation totally reverted the effects of malnutrition on surfactant phospholipids $(8.36 \pm 0.94 \mathrm{nmol}$ disaturated phosphatidylcholine/mg wet wt on $d 2$ versus $7.67 \pm 0.44$ $\mathrm{nmol} / \mathrm{mg}$ in controls and $5.55 \pm 0.62 \mathrm{nmol} / \mathrm{mg}$ in untreated malnourished rats, $n=10 ; 2.43 \pm 0.32 \mathrm{nmol}$ disaturated phosphatidylcholine/mg wet wt on $\mathrm{d} 10$ versus $3.26 \pm 0.32$ $\mathrm{nmol} / \mathrm{mg}$ in controls and $1.18 \pm 0.27 \mathrm{nmol} / \mathrm{mg}$ in untreated malnourished rats, $n=8$ ). It is concluded that proteincalorie malnutrition profoundly affects surfactant phospholipid biosynthesis in the perinatal period and that inositol may represent a useful additive to the diet of malnourished neonates for the correction of pulmonary abnormalities. (Pediatr Res 31: 629-635, 1992)
\end{abstract}

\section{Abbreviations}

TPL, total phospholipid

PC, total phosphatidylcholine

DSPC, disaturated phosphatidylcholine

PG, phosphatidylglycerol

Received February 26, 1991; accepted January 8, 1992

Correspondence and reprint requests: Dr. Jacques Bourbon, Centre de Biologie Cellulaire, C.N.R.S., 67 rue Maurice Günsbourg, F-94205 Ivry-sur-Seine cedex, France.

Supported by Grant No. $039159 \mathrm{~K} 12201 \mathrm{D}$ (to V.G.) from the Centre International d'Etudiants et Stagiaires (C.I.E.S., Paris, France)

'On postdoctoral leave from Instituto Nacionál de Enfermedades Respiratorias, Secretaria de Salúd, Mexico
Malnutrition may impair lung development and respiratory function at various levels. Malnutrition may, in fact, be both a cause and a consequence of ventilatory impairment in the perinatal lung (1). In infants with bronchopulmonary dysplasia, a syndrome consecutive to mechanical ventilation in neonates with respiratory problems, growth failure is a major difficulty due to increased metabolic demands, and these infants have been reported to be relatively "calorie deficient" (2). On the other hand, there is general agreement that malnutrition decreases lung oxidative metabolism and anabolic processes including synthesis and secretion of surfactant, the phospholipid-rich alveolar lining material that diminishes lung surface tension and prevents the filling of alveoli with transudate from the capillaries.

Experimentally, the effects of food deprivation upon some lung components representative of surfactant as well as its effects on lung mechanics have been determined in fetal and neonatal rat lungs. A 4-d fasting in the pregnant rat induced a delay in fetal lung maturation characterized by hypocellularity, diminished PC content, decreased glycogen utilization, and lowered surface active properties of surfactant $(3,4)$. In addition, the incorporation of precursor substrates such as glucose, lactate, and palmitate into fetal lung phospholipids was reduced (5). In the young rat, dietary deprivation reduced the pulmonary content of phospholipids, especially $\mathrm{PC}$, and slowed down the de novo synthesis of fatty acids (6), whereas pulmonary elasticity and compliance were decreased (7). A long-term hypoproteic diet administered to pregnant and lactating rats decreased surface tension properties in the lungs of the offspring (4), whereas DSPC, PG and neutral lipids were markedly reduced in lung tissue (8). In the young suckling or weaned rat, this led to lung hypoplasia and altered lung mechanical properties with reduced compliance, reduced elasticity, and augmented resistance to rupture $(9,10)$. The effects of malnutrition on adult lung metabolic responses $(6,11,12)$ and on lung mechanics $(6,7)$ have also been studied. Contradictory results have been obtained, but as a rule damages have been found to be less severe in adults than in younger animals, whose lungs therefore present a greater susceptibility to malnutrition.

To date, however, the consequences on the composition of surfactant material itself have not been studied. A rapid method to separate this fraction in the developing rat (13) has recently been demonstrated to yield a material that fulfills the criteria necessary to be considered pulmonary surfactant, including potent surface activity (14). In previous investigations with whole lung analysis, changes in this lung compartment may have been overshadowed by variations in the same components of the 
nonsurfactant material, which gathers membranes and surfactant precursors. In the present article, we analyze the changes induced by a hypoproteic-hypocaloric diet in the composition of the surfactant and nonsurfactant fractions isolated from lung tissue of rat fetuses and newborns before weaning. We also explored the capacity of intraperitoneal injections of triglycerides and of inositol supplementation in drinking water to revert the effects of malnutrition. The rationale for these supplementations lies in the fact that lipids bring glycerol and fatty acids representing potential precursors for phospholipid biosynthesis $(15,16)$, whereas inositol has been found to have beneficial effects on perinatal lung maturation $(17-20)$.

\section{MATERIALS AND METHODS}

Animals and lung samples. Wistar rats were purchased from the Centre d'Elevage R. Janvier (St.-Berthevin, France) and were housed at the animal room of the Developmental Physiology Laboratory, Collège de France, Paris. As described in detail elsewhere (21), they were mated overnight, and on the following day (d 0 of gestation) vaginal smears were made. Sperm-positive rats were divided into two groups. Half of the pregnant rats were given, from d 0 of gestation, a normal standard diet containing $19 \%$ proteins (UAR-210; U.A.R., Epinay-sur-Orge, France), and the other half received an isocaloric-hypoproteic diet containing only $5 \%$ proteins, the calories provided by the proteins being substituted by an increased amount of carbohydrates. Other components, namely cellulose, lipids, and vitamins, were the same in both diets. However, we observed that rats fed the hypoproteic diet diminished their dietary intake (Table 1), receiving therefore a hypoproteic-hypocaloric regimen. For the supplementation studies, some pregnant rats received the hypoproteic-hypocaloric diet during gestation, and from the day of parturition they were given myo-inositol (Sigma Chemical Co., St. Louis, MO; $4 \% \mathrm{wt} / \mathrm{vol}$ ) in drinking water. Pups from other litters received daily intraperitoneal injections of $0.3 \mathrm{~mL}$ Intralipid $20 \%$ (Kabi Vitrum, Stockholm, Sweden) starting from the day of birth. Intralipid contains purified soya oil, $20 \mathrm{~g}$; purified egg lecithin, $1.2 \mathrm{~g}$; glycerol, $2.25 \mathrm{~g}$, and water up to $100 \mathrm{~mL}$. All the litters were normalized to eight individuals on the day of birth.

For control and malnutrition assays, lungs were obtained between 1000 and $1600 \mathrm{~h}$ from fetuses at 20.5 and $21.5 \mathrm{~d}$ of gestation and from newborns at $0,2,5,10,15$, and $20 \mathrm{~d}$ after parturition. For the supplementation experiments, lungs were collected 2 and $10 \mathrm{~d}$ after birth. The animals were rapidly bled by cutting the neck vessels. Their lungs were removed immediately, wiped briefly to remove blood, dropped into liquid nitrogen and then stored at $-25^{\circ} \mathrm{C}$ until further use. The sex of the animals was determined by observation of the anal-genital distance. Three different litters and an equal number of males and females were used for each group of determinations.

Wet weight was determined on frozen lungs. Dry weight was determined after $20 \mathrm{~h}$ of dessication in an oven at $110^{\circ} \mathrm{C}$.

Protein, DNA, and glycogen determinations. Total proteins

Table 1. Daily food intake in normal $(N)$ and malnourished $(M)$ pregnant and lactating rats*

\begin{tabular}{cccc}
\hline & \multicolumn{3}{c}{ Food intake $(\mathrm{g} / \mathrm{d})$} \\
\hline \multirow{2}{*}{ Pregnancy } & 1st wk & N & $16.0 \pm 4.6$ \\
& & M & $13.9 \pm 3.4$ \\
& 2nd wk & N & $19.6 \pm 5.2$ \\
& & M & $15.8 \pm 3.0 \dagger$ \\
& 3rd wk & N & $26.0 \pm 1.6$ \\
& & M & $8.6 \pm 4.6 \dagger$ \\
Lactation & 1st wk & N & $35.6 \pm 25.0$ \\
& & M & $6.6 \pm 3.3 \dagger$
\end{tabular}

* Values are means \pm SD of 10 determinations.

$\dagger$ Significant difference with normal rats for $p<0.05$ using $t$ test. were determined by the Biuret method on lung homogenates and in the surfactant fractions after lipid extraction, using BSA (Sigma, fraction V) as a reference. DNA was measured on the pellet obtained after delipidation of tissue by the diphenylamine method of Burton (22), using calf thymus DNA (Sigma) as a reference. Glycogen was analyzed in lungs from 20.5- and 21.5$\mathrm{d}$-old fetuses and 0 - and 2-d-old neonates by the method of Chan and Exton (23).

Surfactant fraction isolation. Surfactant and nonsurfactant fractions were isolated by sucrose density centrifugation, according to the method of Frosolono et al. (24), as revised by Sanders and Longmore (25) and adapted to small size samples by Rieutort et al. (13). The lung samples were homogenized in ice-cold 10 $\mathrm{mM}$ Tris- $\mathrm{HCl}$ buffer, $\mathrm{pH} 7.4$, containing $1 \mathrm{mM}$ EDTA and 154 $\mathrm{mM} \mathrm{NaCl}$. All sucrose solutions were prepared in this buffer, and ultracentrifugations were as described previously (26). The presumed surfactant fraction was obtained as the Frosolono's 1B band at the interface between 0.25 and $0.68 \mathrm{M}$ sucrose layers (14). It has been shown to be constituted principally of lamellar bodies (14). A tracer dose of a radioactive ${ }^{14} \mathrm{C}$ surfactant fraction (in vivo incorporation of ${ }^{14} \mathrm{C}$-choline) was added to each sample to determine recovery at the end of the procedure. Nonsurfactant fraction gathered pellets and supernatants above and below the surfactant band of each centrifugation. It was composed of nuclei, mitochondria, microsomes, lysosomes, and cytosol (26).

Phospholipid analysis. Lipids were extracted overnight from surfactant and nonsurfactant fractions by $4 \times$ vol of Bligh and Dyer solution (chloroform:methanol:water $1: 2: 0.8, \mathrm{vol} / \mathrm{vol} / \mathrm{vol}$ ) or chloroform:methanol $2: 1(\mathrm{vol} / \mathrm{vol})$, respectively. Addition of trace amounts of ${ }^{3} \mathrm{H}$ or ${ }^{14} \mathrm{C}$ dipalmitoylphosphatidylcholine (Amersham-France, Les Ulis, France) allowed evaluation of recovery during processing and phospholipid analysis of surfactant and nonsurfactant fractions, respectively. Phospholipids were separated by two-dimensional thin-layer chromatography as previously described (27). DSPC was extracted from total PC by the osmium tetroxide method of Mason et al. (28). Phosphate amounts were determined after phospholipid mineralization according to Ames and Dubin (29).

Reagents and solvents of analytical grade and silica gel plates were purchased from Sigma, Merck (Darmstadt, Germany), or Prolabo (Paris, France).

Statistical methods. Developmental changes in composition of surfactant and nonsurfactant fractions as well as those induced by malnutrition and supplementation trials were analyzed using analysis of variance. The "q" test was used to make comparisons between specific groups of data.

\section{RESULTS}

Protein-calorie malnutrition in rats during gestation and lactation resulted in a significant deficit in body weight and in wet and dry lung weights (Fig. 1). Relative to body weight, fetal lungs from protein-calorie malnourished rats grew at a substantially slower rate than those from fetuses whose mother received a normal diet (ratio on $\mathrm{d} 20.5: 2.7 \pm 0.1$ as compared with $3.1 \pm$ $0.1 ; p<0.05)$. On the contrary, lungs from malnourished rats aged 15 to $20 \mathrm{~d}$ after birth had an increased lung to body weight ratio relative to rats fed the normal diet $(1.8 \pm 0.1$ compared with $0.96 \pm 0.04 ; p<0.05$ ).

Total lung protein, DNA, and cellularity varied significantly during the period of time studied $[F=6.901(7-40), p<0.05$ for proteins; $F=6.338(7-40), p<0.05$ for DNA; and $F=13,876(7$. $40), p<0.05$ for cellularity]. Total lung proteins also varied significantly in malnourished rats $[F=4.08(1-80), p<0.05]$. They were significantly decreased as compared with controls only on d 20.5 of gestation and $2 \mathrm{~d}$ after parturition. DNA was increased on $\mathrm{d} 20.5$ of gestation and $5 \mathrm{~d}$ postnally and decreased on d 15 after birth (Table 2). Accordingly, lung cellularity as reflected by the protein to DNA ratio was modified at these stages $[F=69.633(1-80), p<0.05]$. Lungs from $20.5-\mathrm{d}$ mal- 


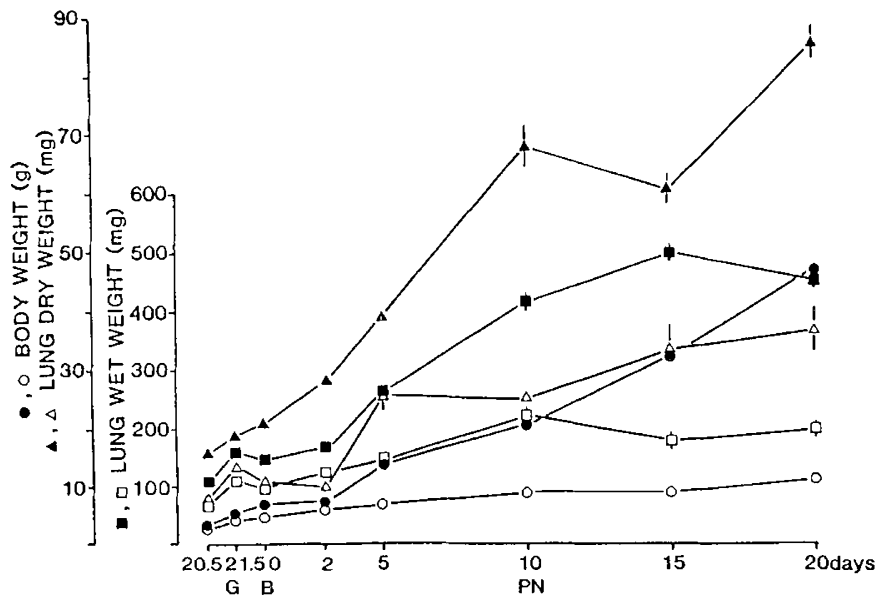

Fig. 1. Changes in body weight (circles), lung wet weight (squares), and lung dry weight (triangles) in control (solid symbols) and malnourished (open symbols) rats. $G$, gestation; $B$, birth; and $P N$, postnatal. $V$ alues are means \pm SEM. Differences between control and malnourished animals are significant for the three parameters at all stages $(0.001<p$ $<0.05)$.

Table 2. Changes in lung protein and DNA concentrations in normal $(N)$ and malnourished $(M)$ developing rats*

\begin{tabular}{cccc}
\hline & & $\begin{array}{c}\text { Protein } \\
(\mathrm{mg} / \mathrm{g} \text { wet } w)\end{array}$ & $\begin{array}{c}\text { DNA } \\
(\mathrm{mg} / \mathrm{g} \text { wet wt })\end{array}$ \\
\hline Gestation & & & \\
d 20.5 & $\mathrm{N}$ & $103.8 \pm 21.2$ & $12.9 \pm 1.2$ \\
& $\mathrm{M}$ & $80.3 \pm 5.2$ & $16.3 \pm 1.2$ \\
d 21.5 & $\mathrm{N}$ & $97.2 \pm 7.3$ & $12.3 \pm 0.4$ \\
Birth & $\mathrm{M}$ & $96.6 \pm 17.4$ & $12.4 \pm 1.1$ \\
d 0 & $\mathrm{N}$ & $160.2 \pm 33.0$ & $19.8 \pm 1.5$ \\
& $\mathrm{M}$ & $141.4 \pm 38.4$ & $17.8 \pm 3.0$ \\
Postnatal & & & \\
d 2 & $\mathrm{N}$ & $163.1 \pm 42.2$ & $10.3 \pm 1.8$ \\
& $\mathrm{M}$ & $118.9 \pm 16.4$ & $11.5 \pm 1.5$ \\
d 5 & $\mathrm{N}$ & $101.3 \pm 11.4$ & $10.2 \pm 0.5$ \\
& $\mathrm{M}$ & $122.0 \pm 24.0$ & $11.3 \pm 1.2$ \\
d 10 & $\mathrm{N}$ & $133.9 \pm 25.7$ & $16.9 \pm 2.4$ \\
& $\mathrm{M}$ & $124.5 \pm 8.5$ & $17.4 \pm 2.7$ \\
d 15 & $\mathrm{N}$ & $124.4 \pm 16.5$ & $14.8 \pm 2.0$ \\
& $\mathrm{M}$ & $128.9 \pm 12.7$ & $10.9 \pm 1.5$ \\
d 20 & $\mathrm{N}$ & $126.0 \pm 8.9$ & $10.9 \pm 1.3$ \\
& $\mathrm{M}$ & $119.0 \pm 16.2$ & $11.8 \pm 1.7$ \\
\hline
\end{tabular}

*Values are means \pm SD of six determinations (six individuals from three different litters). Comparison was achieved through analysis of variance. Variations with time were significant for proteins and for DNA $[F=6.901 /(7-40), p<0.05$ and $F=6.338 /(7-40), p<0.05$, respectively]. Effects of malnutrition were significant for proteins only $[F=4.802(1-$ $80), p<0.05]$.

nourished fetuses had more numerous but smaller cells than control lungs (protein/DNA ratio decreased from $8.1 \pm 1.8$ to $4.9 \pm 0.5, n=6 ; p<0.05$ ); lungs of 2-d-old-malnourished rats showed the same number but smaller sized cells (protein/DNA ratio decreased from $16 \pm 3.6$ to $10.6 \pm 2.3, n=6 ; p<0.05$ ), whereas lungs of $15-\mathrm{d}$-old malnourished rats contained fewer, smaller cells (protein/DNA ratio increased from $8.6 \pm 1.7$ to $12.1 \pm 2.2, n=6 ; p<0.05)$. Lung water content was increased from 85 to $91 \%(n=6 ; p<0.05)$ in the malnourished newborns aged 0,2 , and $10 \mathrm{~d}$. Malnutrition also resulted in a higher glycogen concentration on $\mathrm{d} 2$ after birth, which reveals a delay in glycogen utilization (Fig. 2).

The evolution of concentrations in TPL and in various phospholipid species in the surfactant and nonsurfactant fractions of
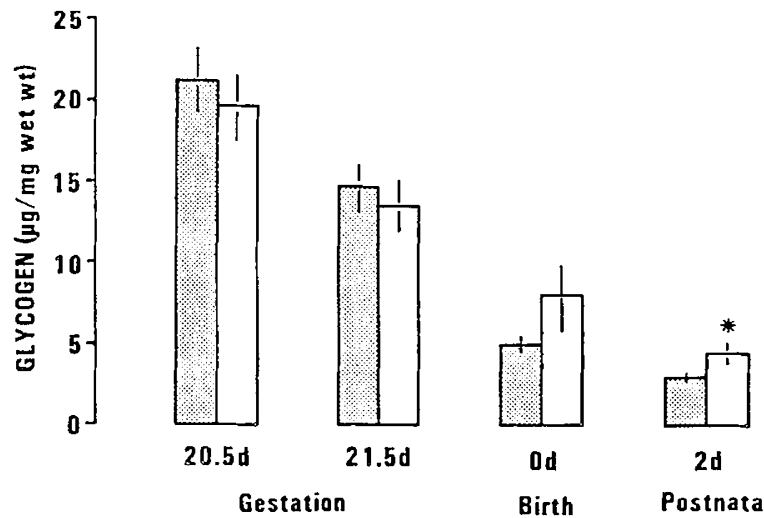

Fig. 2. Changes in glycogen concentration in control (gray columns) and malnourished (white columns) rats. Values are means \pm SEM of six determinations. ${ }^{*}$, Significant difference from controls $(p<0.05)$.

normal and malnourished rat lungs is depicted in Figure 3 and Table 3. It should be noted that there are important variations in the phospholipid composition of these fractions during the perinatal development of the lung in the animals receiving a normal diet. There were two marked phases of surfactant phospholipid accumulation; the first one took place between gestational $\mathrm{d} 20.5$ and 21.5 and the second and greatest one between birth and the 2 nd postnatal day, with concentration peaking at the latter stage (Fig. 3). These changes were statistically significant for all surfactant phospholipids [for TPL, $F=9.875(7-70), p<$ 0.05 ; for PC, $F=8.313(7-70), p<0.05$; and for DSPC, $F=$ $25.558(7-70), p<0.05]$. Two peaks were also observed in the nonsurfactant fraction at the same stages but were proportionally less pronounced, although statistically significant [for TPL, $F=$ 12.137(7-75), $p<0.05$; for PC, $F=30.659(7-76), p<0.05$; and for DSPC, $F=27.715(7-75), p<0.05]$.

In response to the malnutrition, there was a significant increase in all phospholipid concentrations in fetuses aged $20.5 \mathrm{~d}$ that was lost afterwards $[F=53.906(1-111) ; p<0.05]$. In particular, DSPC was increased 1.8 times and PG 6 times in surfactant. Decreases were seen in components of the surfactant fraction of the malnourished rats, principally on $\mathrm{d} 0[F=21.019(1-154), p$ $<0.05], 2[F=34.554(1-126), p<0.05]$, and $10[F=21.393(1-$ $130), p<0.05]$ after birth, whereas the nonsurfactant fraction was diminished mostly on d 21.5 of gestation $[F=198.253(1-$ 127), $p<0.05]$ and $5 \mathrm{~d}$ after birth $[F=12.547(1-140), p<0.05]$. In the surfactant fraction, PC, DSPC, and PG were mostly affected. DSPC was reduced to 23 and $20 \%$ of TPL versus 47 and $42 \%$ in controls on the day of birth and the 10th d, respectively (Fig. 3). PG was reduced to $2.7 \%$ of TPL versus $5.6 \%$ on the 2 nd $\mathrm{d}$. It was also reduced in the nonsurfactant fraction at this stage. By contrast, PG was significantly increased in both fractions on $\mathrm{d} 15$. There was an apparent and transient disappearance of malnutrition effects on the surfactant fraction $5 \mathrm{~d}$ after birth, which was in fact a consequence of the fall in phospholipid concentrations in normal lungs at this age. Total protein content of surfactant fraction was also reduced during fetal stages and 2 and $5 \mathrm{~d}$ after birth (data not shown). In the nonsurfactant fraction, sphingomyelin, phosphatidylserine, and phosphatidylethanolamine, which are found predominantly in membranes, were mostly influenced (Table 3, d 0, 5 and 10). DSPC was proportionally less affected than it was in the surfactant fraction (Fig. 3).

Malnourished rats treated with lipid supplementation showed an increased lung protein concentration $2 \mathrm{~d}$ after birth and a decreased glycogen concentration when compared with untreated malnourished rats (Table 4). Surfactant phospholipids as well as nonsurfactant phospholipids, however, remained significantly decreased in newborn rats aged $2 \mathrm{~d}$ (Tables 5 and 6 ). By contrast, on postnatal d 10, exogenous lipids enhanced PC, DSPC, and 
$n m o l P_{j} / m g w w$
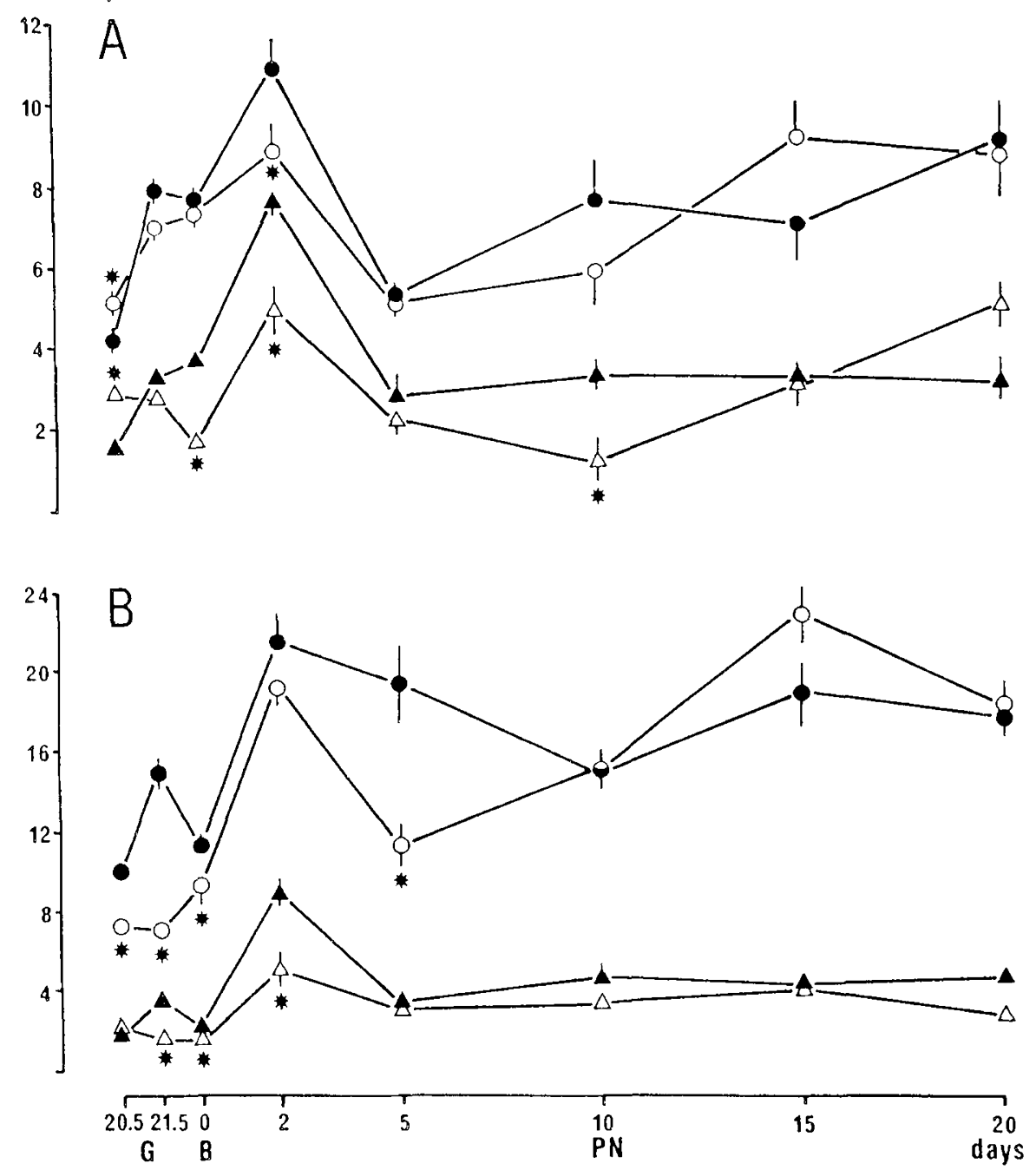

Fig. 3. Changes in TPL (circles) and DSPC (triangles) concentrations in control (solid symbols) and malnourished (open symbols) rats in the surfactant $(A)$ and the nonsurfactant $(B)$ fractions. $G$, gestation; $B$, birth; and $P N$, postnatal. Values are means \pm SEM of eight to 10 determinations. *. Significant difference from controls $(p<0.05)$.

PG concentrations in surfactant, although there was not full restoration to normal values (Table 5).

Inositol treatment of malnourished rats resulted in lowered lung weight, higher protein concentration, and decreased glycogen content when compared with lungs of untreated malnourished rats (Table 4). Surfactant phospholipid analysis revealed that concentrations of all phospholipids were almost restored to normal values by inositol treatment at both stages (Table 5). Phospholipid concentrations in the nonsurfactant fraction were decreased by inositol treatment $2 \mathrm{~d}$ after birth but increased in young rats aged $10 \mathrm{~d}$ (Table 6).

\section{DISCUSSION}

Pulmonary surfactant, which prevents the collapse of alveoli during expiration and the filling of alveoli with transudate from the capillaries, is composed of phospholipids, of which the principal component both quantitatively and functionally is DSPC, and proteins, which also play an important functional role. Malnutrition interferes with lung oxidative metabolism and precursor availability and, therefore, should decrease synthesis of surfactant components. Previous studies have explored changes in the composition of whole lung tissue. The aim of the present study was to determine more specifically changes in the composition of an isolated surfactant fraction induced by a hypoproteichypocaloric diet in rat fetuses and newborns before weaning and to explore the putative restoring effects of inositol and a neutral lipid mixture supplementation.

Fetuses and newborns from malnourished mothers had strongly diminished body and lung weights, as had been reported previously $(4,5,8)$. Similar protein and DNA concentrations were found in normally fed and malnourished rats at most of the ages studied, implying that the cellularity of the lungs was little affected. However, on d 20.5 of gestation, fetal lungs were hyperplastic in malnourished litters, whereas on $\mathrm{d} 2$ after birth the cell size was reduced in spite of unchanged number, and on d 15 after birth there were hypocellularity and cell enlargement. No changes in the cellularity of malnourished fetal lungs had been observed by Rhoades and Ryder (5). Kalenga and Henquin $(9,10)$ had reported that lungs from malnourished rats contain the same number of cells as normal lungs, but that the cells are of a smaller size, which corresponds to the situation encountered on the 2 nd postnatal day in the present study. Our results also show that malnutrition slows down the mobilization of lung glycogen stores after birth, which is consistent with the previous findings by Curle and Adamson (3). This delay in glycogen breakdown with possible reduction of glycogen utilization for providing precursors of surfactant lipids $(26,27)$ appears to reflect a delay in perinatal lung biochemical maturation. Changes in water content suggest that malnutrition also decreased lung fluid reabsorption at birth.

It has been previously reported that food restriction, even for 
Table 3. Changes in phospholipid concentrations in normal $(N)$ and malnourished $(M)$ developing rats in surfactant and nonsurfactant fractions*

\begin{tabular}{|c|c|c|c|c|c|c|c|c|}
\hline & \multirow[b]{2}{*}{ Day } & & \multicolumn{6}{|c|}{ Phospholipids (nmol/mg wet lung weight) } \\
\hline & & & $\mathrm{PC}$ & $\mathrm{Sm}$ & PS & PI & $\mathrm{PE}$ & PG \\
\hline \multicolumn{9}{|c|}{ Surfactant fraction } \\
\hline \multirow[t]{4}{*}{ G } & 20.5 & $\mathrm{~N}$ & $2.56 \pm 0.78$ & $0.02 \pm 0.05$ & $0.01 \pm 0.01$ & $0.01 \pm 0.01$ & $0.04 \pm 0.01$ & $0.01 \pm 0.00$ \\
\hline & & M & $3.19 \pm 0.76$ & $0.07 \pm 0.02$ & $0.26 \pm 0.20$ & $0.31 \pm 0.18$ & $0.59 \pm 0.16$ & $0.06 \pm 0.04$ \\
\hline & 21.5 & $\mathrm{~N}$ & $4.41 \pm 1.65$ & $0.25 \pm 0.09$ & $0.12 \pm 0.05$ & $0.19 \pm 0.09$ & $0.47 \pm 0.16$ & $0.34 \pm 0.16$ \\
\hline & & M & $4.06 \pm 1.13$ & $0.11 \pm 0.03$ & $0.06 \pm 0.02$ & $0.18 \pm 0.05$ & $0.56 \pm 0.15$ & $0.27 \pm 0.07$ \\
\hline \multirow[t]{2}{*}{ B } & 0 & $N$ & $4.79 \pm 0.96$ & $0.07 \pm 0.03$ & $0.08 \pm 0.06$ & $0.11 \pm 0.07$ & $0.29 \pm 0.18$ & $0.26 \pm 0.20$ \\
\hline & & M & $2.52 \pm 1.19$ & $0.45 \pm 0.33$ & $0.26 \pm 0.26$ & $0.18 \pm 0.11$ & $0.46 \pm 0.21$ & $0.32 \pm 0.23$ \\
\hline \multirow[t]{10}{*}{ PN } & 2 & $\mathrm{~N}$ & $7.84 \pm 0.60$ & $0.35 \pm 0.13$ & $0.84 \pm 0.41$ & $0.34 \pm 0.07$ & $1.25 \pm 0.31$ & $0.62 \pm 0.32$ \\
\hline & & $M$ & $5.34 \pm 1.31$ & $0.46 \pm 0.23$ & $0.34 \pm 0.18$ & $0.31 \pm 0.23$ & $0.67 \pm 0.21$ & $0.24 \pm 0.12$ \\
\hline & 5 & $N$ & $3.22 \pm 1.16$ & $0.19 \pm 0.12$ & $0.23 \pm 0.14$ & $0.17 \pm 0.11$ & $0.60 \pm 0.34$ & $0.22 \pm 0.10$ \\
\hline & & M & $3.62 \pm 1.29$ & $0.18 \pm 0.12$ & $0.10 \pm 0.05$ & $0.15 \pm 0.09$ & $0.66 \pm 0.19$ & $0.16 \pm 0.13$ \\
\hline & 10 & $\mathrm{~N}$ & $4.84 \pm 2.13$ & $0.20 \pm 0.19$ & $0.10 \pm 0.12$ & $0.17 \pm 0.15$ & $0.72 \pm 0.23$ & $0.22 \pm 0.13$ \\
\hline & & M & $2.70 \pm 0.68$ & $0.15 \pm 0.13$ & $0.06 \pm 0.06$ & $0.02 \pm 0.02$ & $0.38 \pm 0.28$ & $0.18 \pm 0.12$ \\
\hline & 15 & $\mathrm{~N}$ & $4.06 \pm 0.96$ & $0.22 \pm 0.11$ & $0.37 \pm 0.21$ & $0.18 \pm 0.12$ & $0.65 \pm 0.15$ & $0.22 \pm 0.08$ \\
\hline & & M & $4.73 \pm 1.05$ & $0.21 \pm 0.06$ & $0.21 \pm 0.11$ & $0.18 \pm 0.04$ & $0.75 \pm 0.15$ & $0.40 \pm 0.08$ \\
\hline & 20 & $\mathrm{~N}$ & $4.58 \pm 1.52$ & $0.25 \pm 0.12$ & $0.25 \pm 0.13$ & $0.19 \pm 0.12$ & $1.03 \pm 0.44$ & $0.40 \pm 0.14$ \\
\hline & & M & $6.10 \pm 2.32$ & $0.36 \pm 0.31$ & $0.34 \pm 0.18$ & $0.22 \pm 0.18$ & $1.09 \pm 0.49$ & $0.42 \pm 0.31$ \\
\hline \multicolumn{9}{|c|}{ Nonsurfactant fraction } \\
\hline \multirow[t]{4}{*}{$\mathrm{G}$} & 20.5 & $\mathrm{~N}$ & $4.19 \pm 0.76$ & $0.38 \pm 0.19$ & $0.23 \pm 0.14$ & $0.30 \pm 0.15$ & $2.34 \pm 0.64$ & $0.16 \pm 0.05$ \\
\hline & & $M$ & $2.58 \pm 0.61$ & $0.39 \pm 0.20$ & $0.17 \pm 0.06$ & $0.27 \pm 0.07$ & $1.51 \pm 0.36$ & $0.14 \pm 0.06$ \\
\hline & 21.5 & $\mathrm{~N}$ & $6.58 \pm 0.86$ & $0.62 \pm 0.13$ & $0.81 \pm 0.37$ & $0.26 \pm 0.09$ & $2.96 \pm 0.51$ & $0.22 \pm 0.06$ \\
\hline & & $\mathrm{M}$ & $3.50 \pm 1.09$ & $0.27 \pm 0.10$ & $0.23 \pm 0.09$ & $0.38 \pm 0.58$ & $1.28 \pm 0.41$ & $0.22 \pm 0.26$ \\
\hline \multirow[t]{2}{*}{ B } & 0 & $\mathrm{~N}$ & $6.90 \pm 0.98$ & $1.22 \pm 0.74$ & $0.45 \pm 0.52$ & $0.26 \pm 0.14$ & $2.76 \pm 0.93$ & $0.31 \pm 0.15$ \\
\hline & & M & $6.62 \pm 1.94$ & $0.55 \pm 0.24$ & $0.43 \pm 0.21$ & $0.32 \pm 0.12$ & $2.04 \pm 0.53$ & $0.30 \pm 0.12$ \\
\hline \multirow[t]{10}{*}{ PN } & 2 & $\mathrm{~N}$ & $13.56 \pm 3.64$ & $0.99 \pm 0.30$ & $0.81 \pm 0.52$ & $0.58 \pm 0.16$ & $3.39 \pm 0.72$ & $0.71 \pm 0.28$ \\
\hline & & M & $12.49 \pm 2.08$ & $1.25 \pm 0.45$ & $0.94 \pm 0.89$ & $0.51 \pm 0.15$ & $3.08 \pm 0.77$ & $0.46 \pm 0.09$ \\
\hline & 5 & $N$ & $9.34 \pm 2.36$ & $1.03 \pm 0.54$ & $0.73 \pm 0.40$ & $0.59 \pm 0.27$ & $2.09 \pm 0.79$ & $0.48 \pm 0.22$ \\
\hline & & M & $7.60 \pm 3.25$ & $1.03 \pm 1.14$ & $0.23 \pm 0.22$ & $0.10 \pm 0.12$ & $2.86 \pm 2.01$ & $0.09 \pm 0.10$ \\
\hline & 10 & $\mathrm{~N}$ & $7.28 \pm 0.96$ & $1.14 \pm 0.38$ & $1.37 \pm 0.88$ & $0.33 \pm 0.21$ & $2.90 \pm 0.69$ & $0.26 \pm 0.10$ \\
\hline & & M & $7.58 \pm 0.80$ & $0.80 \pm 0.27$ & $0.55 \pm 0.29$ & $0.29 \pm 0.15$ & $2.57 \pm 0.64$ & $0.30 \pm 0.13$ \\
\hline & 15 & $\mathrm{~N}$ & $8.95 \pm 1.68$ & $0.50 \pm 0.46$ & $0.51 \pm 0.38$ & $0.37 \pm 0.14$ & $2.07 \pm 1.19$ & $0.25 \pm 0.12$ \\
\hline & & $M$ & $10.56 \pm 3.41$ & $1.24 \pm 0.50$ & $0.94 \pm 0.50$ & $0.65 \pm 0.24$ & $2.82 \pm 0.86$ & $0.61 \pm 0.24$ \\
\hline & 20 & $\mathrm{~N}$ & $10.77 \pm 1.50$ & $1.02 \pm 0.35$ & $0.62 \pm 0.36$ & $0.38 \pm 0.12$ & $4.86 \pm 1.23$ & $0.34 \pm 0.10$ \\
\hline & & M & $10.54 \pm 2.16$ & $1.15 \pm 0.28$ & $0.78 \pm 0.15$ & $0.53 \pm 0.18$ & $3.05 \pm 1.50$ & $0.51 \pm 0.16$ \\
\hline
\end{tabular}

* Values are means \pm SD of eight to 10 determinations (eight to 10 individuals from three different litters). Differences were tested through analysis of variance. Changes with time were statistically significant for every phospholipid $(p<0.05)$. The effects of malnutrition were significant at all stages except on $\mathrm{d} 5$ for the surfactant fraction and on $\mathrm{d} 10$ and 15 for the nonsurfactant fraction (see text for $F$ values). G, gestation; B, birth; PN, postnatal; Sm, sphingomyelin; PS, phosphatidylserine; PI, phosphatidylinositol; and PE, phosphatidylethanolamine.

a small period of time, severely affects lung mechanics and surfactant synthesis, especially during development $(4,5,9,10)$. In other words, fetuses and newborns with increasing surfactant pool are affected the most, whereas adult mature lungs seem to resist better the effects of malnutrition $(6,7,25)$. A significant increase in lung surfactant phospholipids, particularly DSPC and PG, was found, however, in 20.5-d-old malnourished fetuses, which reflects a transiently accelerated lung maturation. This may result from a fetal stress induced by malnutrition, inasmuch as mediators released during stress are well known to accelerate lung maturation. Although this stress is probably sustained, lungs from malnourished rats appear no longer to be able to follow the maturational rhythm after this stage, particularly after birth, possibly because they are no longer protected by maternal compensatory mechanisms. We found a multiphasic pattern for the effects of malnutrition on surfactant and nonsurfactant phospholipids that probably reflects the alternation of phases of rapid growth and surfactant synthesis described to occur during perinatal lung maturation $(21,30)$. Peculiarly, intense synthesis phases are illustrated by the increase in surfactant phospholipid concentration seen in normal rats on $\mathrm{d} 21.5$ of gestation and 2 $\mathrm{d}$ after birth. The surfactant fraction was mostly affected in malnourished lungs during these synthesis phases around birth, and the nonsurfactant fraction was mostly altered during the growth phases, particularly on d 5 postpartum. Furthermore, the apparent recovery in surfactant phospholipid concentrations in malnourished lungs $5 \mathrm{~d}$ after birth seems to be due to a decrease in the relative content of these components in the normal lung rather than to an increased synthesis in the malnourished animals. In contrast, an actual recovery of phospholipid concentration in surfactant from malnourished rats seemed to take place on $\mathrm{d} 15$ to 20 after birth, despite the persistent growth deficit. Although no functional evaluation of surfactant was made, it should be underlined that DSPC, the main functionally active component of surfactant, was the most affected in the surfactant fraction. With a similar diet, a reduced compliance of the lung of rat pups has been previously evidenced (9), which was likely related to reduced surfactant DSPC content. By contrast, sphingomyelin, phosphatidylserine, and phosphatidylethanolamine, which are known to be more abundant in membranes, were the most influenced components in the nonsurfactant fraction. It should also be pointed out that, whatever the changes in surfactant component concentrations, the total amount of material per lung was considerably reduced at all stages, which reflects a profoundly diminished phospholipid biosynthetic potential. The more marked changes in surfactant compartment as compared with extrasurfactant pools of phospholipids indicate a greater susceptibility of surfactant biosynthesis to malnutrition.

In supplementation trials, we investigated the effects of triglycerides, because these molecules bring glycerol and fatty acids, 
Table 4. Effects of inositol and Intralipid treatments on body weight, lung wet weight, and lung protein, DNA, and glycogen concentrations*

\begin{tabular}{lrcc} 
& Day & Inositol & Intralipid \\
\hline Body weight (g) & 2 & $4.6 \pm 0.6$ & $4.8 \pm 0.4$ \\
& 10 & $7.5 \pm 0.7$ & $5.2 \pm 0.5$ \\
Lung wet weight (mg) & 2 & $95.6 \pm 24.3$ & $115.8 \pm 19.7$ \\
& 10 & $158.4 \pm 50.5$ & $102.0 \pm 10.3$ \\
DNA (mg/g wet wt) & 2 & $11.4 \pm 1.9$ & $8.7 \pm 0.6$ \\
& 10 & $12.2 \pm 2.7$ & $10.2 \pm 3.4$ \\
Proteins (mg/g wet wt) & 2 & $314.0 \pm 59.5$ & $287.4 \pm 81.0$ \\
& 10 & $284.5 \pm 47.7$ & $109.0 \pm 9.3$ \\
Glycogen (mg/g wet wt) & 2 & $1.7 \pm 0.6$ & $1.4 \pm 0.3$ \\
\hline
\end{tabular}

* Values are means $\pm \mathrm{SD}$ of six determinations. Comparison between these experimental groups and untreated malnourished or control rats (see Table 2) was achieved through analysis of variance. "q" test was used to make comparisons between specific groups of data and the difference was considered significant when $p<0.05$. Body weight and lung wet weight were not increased by supplementation trials. There were significant changes in lung proteins, DNA, and glycogen. There was a decrease in DNA on d 10 with Intralipid treatment and an increase in lung proteins at both ages with both inositol and Intralipid treatments. Glycogen was down to normal levels when compared with untreated malnourished rats (see Fig. 2).

Table 5. Effects of malnutrition and of inositol and Intralipid treatments on surfactant phospholipid concentrations (nmol/mg lung wet wt)*

\begin{tabular}{lcccc}
\hline & Normal & Malnourished & Inositol & Intralipid \\
\hline Day 2 & & & & \\
TPL & $11.00 \pm 1.92$ & $9.02 \pm 2.15$ & $12.14 \pm 4.12$ & $7.51 \pm 2.36$ \\
PC & $7.84 \pm 0.60$ & $6.80 \pm 3.42$ & $9.97 \pm 3.91$ & $4.80 \pm 1.60$ \\
DSPC & $7.67 \pm 1.32$ & $5.55 \pm 1.96$ & $8.36 \pm 2.96$ & $4.51 \pm 1.54$ \\
Sm & $0.35 \pm 0.13$ & $0.46 \pm 0.23$ & $0.28 \pm 0.08$ & $0.15 \pm 0.10$ \\
PS & $0.84 \pm 0.41$ & $0.40 \pm 0.26$ & $0.34 \pm 0.33$ & $0.14 \pm 0.05$ \\
PI & $0.34 \pm 0.07$ & $0.31 \pm 0.23$ & $0.22 \pm 0.11$ & $0.15 \pm 0.06$ \\
PE & $1.25 \pm 0.31$ & $0.67 \pm 0.21$ & $1.06 \pm 0.28$ & $0.46 \pm 0.13$ \\
PG & $0.62 \pm 0.32$ & $0.26 \pm 0.10$ & $0.41 \pm 0.22$ & $0.27 \pm 0.07$ \\
Day 10 & & & & \\
TPL & $7.73 \pm 2.35$ & $5.91 \pm 2.52$ & $7.13 \pm 1.70$ & $6.20 \pm 0.85$ \\
PC & $4.84 \pm 2.13$ & $2.70 \pm 0.68$ & $3.62 \pm 0.78$ & $3.76 \pm 0.53$ \\
DSPC & $3.26 \pm 1.03$ & $1.18 \pm 0.87$ & $2.43 \pm 0.97$ & $2.96 \pm 0.61$ \\
Sm & $0.20 \pm 0.19$ & $0.15 \pm 0.13$ & $0.25 \pm 0.10$ & $0.26 \pm 0.10$ \\
PS & $0.10 \pm 0.12$ & $0.06 \pm 0.06$ & $0.15 \pm 0.03$ & $0.17 \pm 0.06$ \\
PI & $0.17 \pm 0.15$ & $0.02 \pm 0.02$ & $0.17 \pm 0.08$ & $0.15 \pm 0.08$ \\
PE & $0.72 \pm 0.33$ & $0.38 \pm 0.28$ & $0.77 \pm 0.19$ & $0.20 \pm 0.10$ \\
PG & $0.22 \pm 0.13$ & $0.18 \pm 0.12$ & $0.21 \pm 0.09$ & $0.36 \pm 0.13$ \\
\hline
\end{tabular}

$*$ Values are means $\pm \mathrm{SD}$ of eight to 10 determinations. Comparison was achieved through analysis of variance: for $\mathrm{d} 2, F=507.678(3-269)$, $p<0.05$, and for d 10,F $=84.689(3-269), p<0.05$, PC, DSPC, and PG were significantly increased at both stages by inositol and on $\mathrm{d} 10$ by Intralipid as compared with untreated malnourished rats. Sm, sphingomyelin; PS, phosphatidylserine; PI, phosphatidylinositol; and PE, phosphatidylethanolamine.

representing potential precursors for synthesis of surfactant phospholipids. Lung possesses a very active lipoprotein lipase and is the first organ to receive chylomicrons from the digestive tract (15). When lipids were injected into the newborns, we did not find any recovery of surfactant components on the 2 nd postnatal day. This may be due to the fact that exogenous fatty acids are not as easily incorporated into surfactant components as endogenous fatty acids (16). In addition, the parenteral mode of administration was possibly not the most optimal route for lipid assimilation. Intralipid was indeed designed for i.v. administration, but this route was not practicable in newborn rats. A partial recovery was, however, seen on the 10th d. Although this may not result from the nutritional modification caused by Intralipid
Table 6. Effects of malnutrition and of inositol and Intralipid treatments on nonsurfactant phospholipid concentrations (nmol) mg lung wet $w t$ *

\begin{tabular}{lrrrr}
\hline & \multicolumn{1}{c}{ Normal } & Malnourished & Inositol & \multicolumn{1}{c}{ Intralipid } \\
\hline Day 2 & & & & \\
TPL & $21.47 \pm 4.78$ & $19.32 \pm 3.42$ & $15.47 \pm 1.85$ & $24.85 \pm 5.51$ \\
PC & $13.56 \pm 3.60$ & $12.49 \pm 2.08$ & $8.49 \pm 1.66$ & $13.62 \pm 5.39$ \\
DSPC & $9.02 \pm 2.90$ & $5.24 \pm 1.92$ & $4.95 \pm 1.12$ & $10.06 \pm 4.13$ \\
Sm & $0.99 \pm 0.30$ & $1.25 \pm 0.45$ & $0.74 \pm 0.42$ & $1.36 \pm 0.78$ \\
PS & $0.81 \pm 0.52$ & $0.94 \pm 0.89$ & $0.09 \pm 0.10$ & $0.96 \pm 0.75$ \\
PI & $0.58 \pm 0.16$ & $0.51 \pm 0.15$ & $0.17 \pm 0.08$ & $0.72 \pm 0.45$ \\
PE & $3.39 \pm 0.72$ & $3.08 \pm 0.77$ & $2.52 \pm 0.85$ & $6.08 \pm 3.11$ \\
PG & $0.71 \pm 0.28$ & $0.46 \pm 0.09$ & $0.17 \pm 0.15$ & $0.62 \pm 0.64$ \\
Day 10 & & & & \\
TPL & $15.12 \pm 3.50$ & $15.29 \pm 1.85$ & $20.86 \pm 5.75$ & $14.59 \pm 1.72$ \\
PC & $7.28 \pm 0.96$ & $7.58 \pm 0.80$ & $10.17 \pm 4.78$ & $7.45 \pm 1.54$ \\
DSPC & $4.69 \pm 1.42$ & $3.86 \pm 0.62$ & $5.49 \pm 2.26$ & $3.41 \pm 0.66$ \\
Sm & $1.14 \pm 0.38$ & $0.80 \pm 0.27$ & $1.78 \pm 0.84$ & $1.04 \pm 0.29$ \\
PS & $1.37 \pm 0.88$ & $0.55 \pm 0.29$ & $1.30 \pm 0.34$ & $0.69 \pm 0.29$ \\
PI & $0.33 \pm 0.21$ & $0.29 \pm 0.15$ & $0.76 \pm 0.43$ & $0.70 \pm 0.21$ \\
PE & $2.90 \pm 0.69$ & $2.57 \pm 0.64$ & $5.36 \pm 3.32$ & $2.74 \pm 0.77$ \\
PG & $0.26 \pm 0.10$ & $0.30 \pm 0.13$ & $0.61 \pm 0.42$ & $0.67 \pm 0.18$ \\
\hline
\end{tabular}

* Values are means \pm SD of eight to 10 determinations. Comparison was achieved through analysis of variance: for $\mathrm{d} 2, F=117.099(3-269)$, $p<0.05$, and for d 10, $F=181.922(3-269), p<0.05$. Phospholipids were significantly decreased by inositol on $\mathrm{d} 2$ and significantly increased on d 10. Sm, sphingomyelin; PS, phosphatidylserine; PI, phosphatidylinositol; and PE, phosphatidylethanolamine.

because of the unusual mode of injection, the observation suggests a potential usefulness of this supplementation.

Inositol supplementation reverted the effects of malnutrition on surfactant phospholipid composition but did not affect its protein concentration. $M y o$-inositol is a six-carbon sugar alcohol that is as abundant as glucose in adults. In newborns and fetuses, its concentration is 2 to 100 times higher than in adults. It has been shown that inositol exerts a trophic action and increases surfactant DSPC concentration in human newborns $(18,20)$. It also reduced mechanical ventilation requirements and decreased the number of deaths in preterm infants suffering from bronchopulmonary dysplasia (19). In our experiments, inositol not only increased surfactant phospholipid concentrations but also diminished glycogen concentration, i.e. it increased its utilization presumably for surfactant biosynthesis (26). Supplementation studies suggest that the lung of the malnourished rat poorly uses exogenous precursors for surfactant lipid biosynthesis, probably because of an overall reduced anabolic activity. Inositol, which exerts a trophic influence, may have stimulated surfactant biosynthesis without providing direct precursors. The alternative possibilities that inositol increased maternal food intake or was itself metabolized cannot be ruled out, however. Inositol has the potential to be converted to glucuronic acid, thus serving as a caloric source. Whatever its actual mode of action, inositol nevertheless appears to be a stimulus for phospholipid biosynthesis in the malnourished rat pup.

It is concluded that there are considerable alterations in the composition of surfactant material isolated from fetal and neonatal rat lung tissue as a result of a hypoproteic-hypocaloric diet. DSPC, the major active component, is particularly affected. The reduction is especially marked at birth when respiration is established. As far as these results can be extended to humans, they may have important consequences for respiratory function, especially if prematurity is associated with malnutrition. Inositol supplementation reverted the effects of malnutrition on phospholipid surfactant composition. The study points out the potential advantage of inositol as an additive to the diet of premature and malnourished infants, in addition to the correction of nutritional deficits. 
Acknowledgments. The authors thank C. Valenza, G. Frebourg, and A. M. Cirinesi for technical assistance. We are grateful to Professor A. Jost for providing the animal care facilities of the Developmental Physiology Laboratory at the Collège de France, Paris.

\section{REFERENCES}

1. Rothkopf MM, Askanazi J 1988 Nutrition and respiration. World Rev Nutr Diet 56:43-55

2. Kurzner SI, Garg M, Bautista DB, Bader B, Merritt RJ, Warburton D, Keens T 1988 Growth failure in infants with bronchopulmonary dysplasia: nutrition and elevated resting metabolic temperature. Pediatrics 81:379-384

3. Curle DC. Adamson IYR 1978 Retarded development of neonatal rat lung by maternal malnutrition. J Histochem Cytochem 26:401-408

4. Faridy EE 1975 Effect of maternal malnutrition on surface activity of fetal lungs in rats. J Appl Physiol 39:535-540

5. Rhoades RA, Ryder DA 1981 Fetal lung metabolism response to maternal fasting. Biochim Biophys Acta 663:621-629

6. Gail DB, Massaro GD, Massaro D 1977 Influence of fasting on the lung. J Appl Physiol 42:88-92

7. Sahebjami H, MacGee J 1985 Effects of starvation on lung mechanics and biochemistry in young and old rats. J Appl Physiol 58:778-784

8. Diop A. Tordet C, Marin L 1986 Influence de la sous-nutrition sur le développement pulmonaire au cours de la période périnatale chez le rat. Collog INSERM 136:259-268

9. Kalenga M, Henquin JC 1987 Alteration of lung mechanics by protein calorie malnutrition in weaned rats. Respir Physiol 68:29-39

10. Kalenga M, Henquin JC 1987 Protein deprivation from the neonatal period impairs lung development in the rat. Pediatr Res 21:45-49

11. d'Amours R, Clerch L, Massaro D 1983 Food deprivation and surfactant in adult rats. J Appl Physiol 55:1413-1417

12. Brown LA, Bliss AS, Longmore W 1984 Effect of the nutritional status on the lung surfactant system: food deprivation and caloric restriction. Exp Lung Res 6:133-147

13. Rieutort M, Farrell PM, Engle MJ, Pignol B, Bourbon JR 1986 Changes in surfactant phospholipids in fetal rat lung from normal and diabetic pregnancies. Pediatr Res 20:650-654

14. Farrell PM, Bourbon JR, Notter RH, Marin L, Nogee LM, Whitsett JA 1990
Relationships among surfactant fraction lipids, proteins and biophysical properties in the developing rat lung. Biochim. Biophys Acta 1044:84-90

15. Hamosh $M$, Hamosh P 1975 Lipoprotein lipase in rat lung. The effect of fasting. Biochim Biophys Acta 380:132-140

16. Patterson CE, Davis KS, Rhoades RA 1988 Regulation of fetal lung disaturated phosphatidylcholine synthesis by de novo palmitate supply. Biochim Biophys Acta 958:60-69

17. Egberts J, Gorree GCM 1984 Inositol affects the turnover of surfactant in the rat. Prog Respir Res 18:183-186

18. Hallman M 1983 Effects of extracellular myo-inositol on surfactant phospholipid synthesis in the fetal rabbit lung. Biochim Biophys Acta 795:67-78

19. Hallman M, Arjomaa P, Hoppu K 1987 Inositol supplementation in respiratory distress syndrome: relationship between serum concentration, renal excretion and lung effluent phospholipids. J Pediatr 110:604-610

20. Hallman M, Saugstad OD, Porreco RP, Epstein BL, Gluck L 1985 Role of myo-inositol in regulation of surfactant phospholipids in the newborn. Early Hum Dev 10:245-254

21. Bourbon JR, Farrell PM, Doucet E, Brown DJ, Valenza C 1987 Biochemical maturation of fetal rat lung: a comprehensive study including surfactant determination. Biol Neonate 52:48-60

22. Burton K 1956 A study of the conditions and mechanisms of the diphenylamine reaction for the colorimetric estimation of the deoxyribonucleic acid. Biochem J 62:315-323

23. Chan TM, Exton JM 1976 A rapid method for the determination of glycogen content and radioactivity in small quantities of tissue or isolated hepatocytes. Anal Biochem 71:96-105

24. Frosolono MF Charms BL, Pawlowski RP, Slivka S 1970 Isolation, characterization and surface chemistry of a surface active fraction from dog lung. $\mathbf{J}$ Lipid Res 11:439-457

25. Sanders RL, Longmore WJ 1975 Phosphatidylglycerol in rat lung. II. Comparison of occurrence, composition and metabolism in surfactant and residual lung fractions. Biochemistry 14:835-840

26. Farrell PM, Bourbon JR 1986 Fetal lung surfactant lipid synthesis from glycogen during organ culture. Biochim Biophys Acta 878:159-167

27. Bourbon JR, Rieutort M, Engle MJ, Farrell PM 1982 Utilization of glycogen for phospholipid synthesis in fetal rat lung. Biochim Biophys Acta 712:382389

28. Mason RJ, Nellenbogen N, Clements JA 1976 Isolation of disaturated phosphatidylcholine with osmium tetroxide. J Lipid Res 17:281-284

29. Ames BN, Dubin DT 1960 The role of polyamines in the neutralization of bacteriophage deoxyribonucleic acid. J Biol Chem 235:769-775

30. Adamson IYR, King GM 1985 Epithelial-mesenchymal interactions in postnatal rat lung growth. Exp Lung Res 8:261-274 